CORRECTION

\title{
Correction to: Mapping perception of China in Central and Eastern Europe
}

\section{Suetyi Lai ${ }^{1} \cdot$ Yidong Cai ${ }^{1}$}

Published online: 17 September 2021

(c) Springer-Verlag GmbH Germany, part of Springer Nature 2021

\section{Correction to: Asia Europe Journal \\ https://doi.org/10.1007/s10308-021-00607-5}

The correct Fig. 7 is the below:

The original article can be found online at https://doi.org/10.1007/s10308-021-00607-5.

\section{Suetyi Lai}

laisuetyi@gdufs.edu.cn

1 Guangdong University of Foreign Studies, Guangzhou, China 


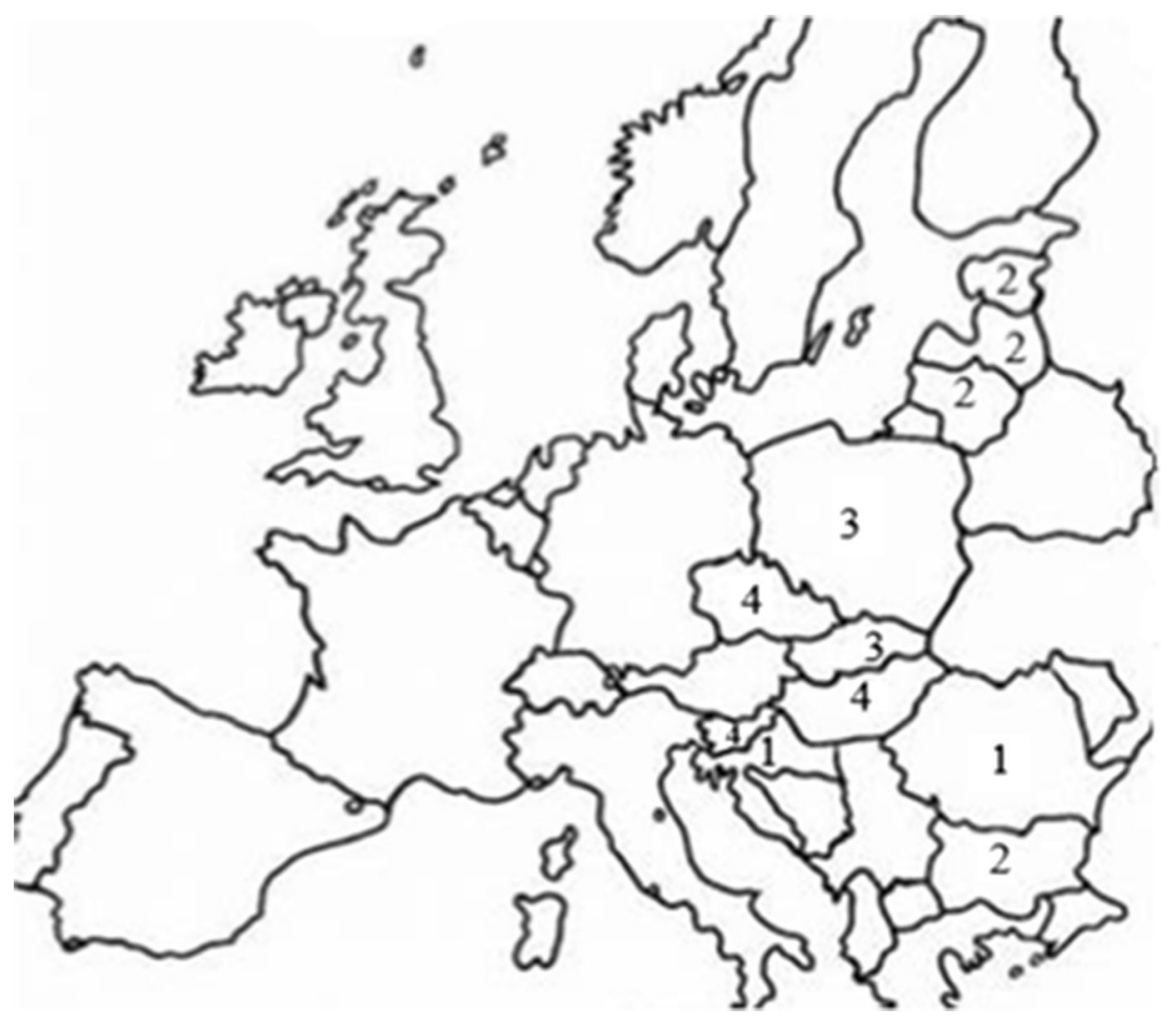

Fig. 7 Four groups of the $11 \mathrm{EU} 16+1$ countries in terms of attitude towards China. ( 1 refers to "Chinafriendly", 2 refers to "China-neutral", 3 refers to "China-polarised" and 4 refers to "China-sceptic")

Publisher's note Springer Nature remains neutral with regard to jurisdictional claims in published maps and institutional affiliations. 